\title{
TINGKAT BERPIKIR MAHASISWA PADA MATA KULIAH GEOMETRI DITINJAU DARI GAYA KOGNITIF
}

\author{
Annisa Prima Exacta ${ }^{1}$, Krisdianto Hadiprasetyo ${ }^{2}$ \\ ${ }^{1,2}$ Universitas Veteran Bangun Nusantara
}

\begin{abstract}
Differences in cognitive styles influence students' mindset and behavior. Students with Field Independent (FI) cognitive style have different mindset with Field Dependent (FD) students. By identifying cognitive style, lecturer needs to understand the concept of material due to the way in explaining it to students. The objectives of this study are to find out: (1) students' thinking level in Geometry who have Field Dependent (FD) cognitive style, (2) students' thinking level in Geometry who have Field Independent (FI) cognitive style. This research is conducted at Teacher Training and Education Faculty of Veteran Bangun Nusantara Sukoharjo in Mathematics Education Department in the academic year of 2017/2018. It is a qualitative descriptive research. Data about thinking levels are obtained from diagnostic tests and interview results, while data on cognitive style are obtained from the results of Group Embedded Figure test (GEFT). Subjects are taken by purposive sampling technique and triangulation method is used as data validation. In analyzing data, the researchers employ some stages consisting of data reduction, data presentation, and conclusion. The results reveal that students' thinking level who have Field Dependent (FD) cognitive style in Geometry course is visualization and pre-analysis, while students' thinking level who have of Field Independent (FI) cognitive style in Geometry course is visualization, analysis, and informal pre-deduction.
\end{abstract}

Keywords:Thinking Level, Cognitive Style, Field Independent (FI), Field Dependent (FD), Geometry.

\section{PENDAHULUAN}

Bahasan tetang pendidikan di Indonesia, mungkin akan muncul pemikiran bahwa masih banyak permasalahan yang menyertainya. Dunia pendidikan sedang mengalami berbagai perubahan sesuai dengan tuntutan dan kebutuhan masyarakat, serta tantangan untuk menjawab berbagai permasalahan lokal dan perubahan global yang terjadi begitu pesat. Perubahan dan permasalahan tersebut diantaranya perkembangan masyarakat, informasi, ilmu pengetahuan, teknologi, seni, dan budaya. Sejalan dengan itu, bangsa Indonesia sedang dihadapkan pada fenomena yang begitu memprihatinkan, yakni rendahnya daya saing sebagai indikator bahwa pendidikan belum mampu menghasilkan sumber daya manusia berkualitas. Ini dibuktikan denganIndeks Pengembangan Manusia (IPM) atau Human Development Index (HDI) Indonesia yang makin menurun, dimana berdasarkan riset United Nations Development Programme (UNDP) melaporkan bahwa Indonesia berada pada peringkat 108 dari 187 negara (pada akhir tahun 2014).

Era globalisasi yang ditandai dengan persaingan kualitas atau mutu, menuntut semua pihak dalam berbagai bidang dan sektor pembangunan untuk senantiasa meningkatkan kompetensinya. Hal tersebut mendudukkan pentingnya upaya peningkatan kualitas pendidikan baik secara kuantitatif maupun kualitatif yang harus dilakukan terus 
menerus, sehingga pendidikan dapat digunakan sebagai wahana dalam membangun watak bangsa (nation character building). Pendidikan merupakan saranauntuk mengembangkan sumber daya manusia. Hal inilah yang menjadikan pendidikan harus memiliki suatu pengembangan atau kemajuan dalam pembelajaran untuk dapat meningkatkan kualitas sumber daya manusia yang merupakan aset utama sebagai modal bangsa dalam membangun negara Indonesia.

Sekolah merupakan sarana pendidikan yang mencakup pendidikan dari tingkat dasar hingga perguruan tinggi. Perguruan tinggi merupakan jenjang pendidikan tertinggi dimana terdapat pengkhususan bidang ilmu yang harus dipelajari. Pada jenjang pendidikan di perguruan tinggi pematangan sumber daya manusia akan dilakukan.

Mohd \& Mahmood (2011), Mathematics is an important subject to many university students. Some are gifted and may effortlessly pass the subject without much difficulty. However, there are still many students who struggle in learning mathematics. Mahasiswa memiliki kemampuan penataan nalar, pembentukan sikap, kemampuan pemecahan masalah, mengkomunikasikan ide-ide dan keterampilan menerapkan matematika. Belajar matematika tentunya tidak cukup dengan hanya menyampaikan materi pelajaran yang sesuai dengan tuntutan kurikulum, tetapi harus disertai dengan makna agar mahasiswa dapat menggunakan kemampuan dan rasa ingin tahunya dengan leluasa dan tanpa terbebani. Hal yang sudah selayaknya menjadi konsep atau cara pandang dosen yang modern dalam proses belajar mengajar, karena pada hakikatnya belajar matematika tidak terletak pada penguasaan matematika sebagai ilmu tetapi bagaimana menggunakan matematika itu dalam mencapai keberhasilan hidup.

Since the 1980s, mathematics educators have agreed that developing problem solving skills should be the focus of mathematics learning (Kuzle, 2013).The general aim of mathematics is stated as making an individual acquire the mathematical knowledge needed in daily basis, teaching how to solve problems, making him/her have a method of solving problems and acquiring reasoning methods (Altun,2008)

Geometri merupakan cabang ilmu matematika yang menyediakan banyak keterampilan dasar dan membantu untuk membangun kemampuan berpikir logika, penalaran analitis dan pemecahan masalah. Mata kuliah Geometri merupakan mata kuliah yang wajib ditempuh mahasiswa prodi Pendidikan Matematika Univet Bantara Sukoharjo. Dalam Geometri, mahasiswa dituntut untuk mengetahui dan mamahami konsep-konsep dasar Geometri antara lain tentang titik, garis, dan bidang. Namun demikian, mahasiswa masih banyak yang belum memahami tentang konsep-konsep pada Geometri dan berdampak pada banyak mahasiswa yang tidak lulus mata kuliah Geometri. 
Berdasarkan data hasil UAS tahun akademik 2016/2017 sebanyak 45\% mahasiswa yang tidak lulus mata kuliah Geometri. Banyaknya mahasiswa yang tidak lulus dapat terjadi karena lemahnya penguasaan materi sehingga pemahaman konsep siswa yang belum maksimal.

Karimah et al (2018) menyatakan bahwa, the difficulty of this learning is the lack of understanding of Geometry concepts that ultimately inhibit the further learning process.Lebih lanjut lagi Carnine (1997) mengungkapkan bahwa, the affect ofmathematics difficulties is cumulative because the development of mathematics skills is based on the previous skills.

Santrock (2007:294) menyatakan bahwa berpikir melibatkan manipulasi dan transformasi informasi dalam memori dengan tujuan membentuk konsep, alasan, pikiran kritis, dan penyelesaian masalah. Sedangkan Purwanto (2010: 43) menyatakan, "Berpikir adalah suatu keaktifan pribadi manusia yang mengakibatkan penemuan yang terarah kepada suatu tujuan". Abdi (2012) menyatakan bahwa the basic characteristic of human being is the ability of thinking.

Zhang (2003) menyatakan bahwa it is widely recognized that investigation the relationship between thinking styles and critical thinking skills can be beneficial for the individual student, teachers, curriculum designers and society. Lebih lanjut lagi, numerous researchershave experimented different ways of teaching and found serious problems in geometry learners:incomplete comprehension of the problem and mathematical symbols, producing proofs based on direct visual elements (Chazan, 1993; Healy \& Hoyles, 2000). Sehingga dapat dikatakan bahwa terdapat hubungan antara tingkat berpikir dalam memahami geometri, jika hal ini tidak segera diketahui ataupun disadari oleh dosen maka dapat menjadi suatu masalah yang serius.

Berdasarkan teori van Hiele, mahasiswa akan melalui lima tingkat berpikir dalam memahami geometri. Masing-masing tingkat berpikir memiliki kriteria tertentu yang terdiri atas tingkat 0 (visualisasi), tingkat 1 (analisis), tingkat 2 (deduksi informal), tingkat 3 (deduksi), dan tingkat 4 (rigor). Masing-masing tingkat berpikir memiliki kriteria tertentu. Pada tingkat 0 (visualisasi), Van Hiele menyatakan bahwa obyek pemikiran pada tingkat 0 adalah bentuk dan seperti apa bentuk itu terlihat. Pada tingkat ini mahasiswamulai mengenalidan menamai bentuk-bentuk geometri didasarkan pada karakteristik dari tampilannya secara visual. Mahasiswa tidak terfokus pada sifat-sifat obyek yang diamati, tetapi memandang obyek sebagai keseluruhan. Mahasiswa belum mampu menyatakan sifat-sifat dari suatu bentuk maupun ide geometri secara jelas (Van de Walle, 2001:309). Pada tingkat ini mahasiswa memandang ruang hanya sebagai 
sesuatu yang ada di sekitar mereka. Konsep geometri lebih dipandang sebagai satu kesatuan, mahasiswa belum mampu menganalisis pada bagian-bagiannya (Crowley, 1987:2). Hoffer (1981) mengemukakan beberapa contoh ketrampilan dasar geometri yang muncul, seperti: kemampuan melihat bentuk, mengenali informasi pada gambar, mampu membuat sketsa obyek geometri.

Pada tingkat 1 (analisis), van Hiele berpendapat bahwa mahasiswa mulai mengenali sifat-sifat dari gambar maupun ide geometri (Hoffer, 1981:14). Sifat-sifat yang ditemukan ini kemudian digunakan untuk mengelompokkan bentuk-bentuk geometri. Bentuk-bentuk geometri ini diamati dan dikenali berdasarkan bagian-bagiannya. Meskipun demikian, hubungan antar bentuk geometri dan sifat-sifatnya belum dapat dijelaskan oleh mahasiswa(Crowley, 1987:2). Keterampilan dasar geometri yang muncul menurut Hoffer (1981) seperti kemampuan dalam mengidentifikasi gambar sebagai bagian dari gambar yang lebih besar, mendeskripsikan dengan benar berbagai sifat pada gambar, memahami bahwa sifat obyek geometri dapat digunakan untuk membedakan obyek geometri.

Pada tingkat deduksi informal, van Hiele berpendapat bahwa mahasiswa dapat membangun hubungan antara sifat-sifat bentuk geometri baik dalam suatu gambar maupun diantara beberapa gambar (Crowley, 1987:3). Definisi dapat dipahami, argumen informal dapat diberikan dan dipahami. Meskipun demikian, mahasiswa pada tahap ini belum memahami arti deduksi secara keseluruhan atau belum memahami aturan dari aksioma. Mahasiswa yang berada pada tingkat 2 secara logis dapat mengurutkan bentuk geometri dan memahami hubungan diantara beberapa ide-ide geometri (Hoffer, 1981:14). The Van Hiele model continues to be the best-known theoretical account of students' learning about shape. The model suggests that children have to take a sequence of levels in a fixed order in their learning about shape (Van Hiele, 1986).

Van Hiele menyatakan bahwa pada tingkat 3 (deduksi) mahasiswa memahami arti deduksi dan aturan-aturan dari postulat, teorema dan pembuktian (Hoffer, 1981:14). Hasil dari pemikiran mahasiswa pada tingkat ini adalah sistem deduktif aksiomatik dari geometri yang berarti bahwa mahasiswa sudah dapat membuktikan dengan dasar aksioma maupun teorema (van de Wall, 2001:310). Mahasiswa yang berada pada tingkat 3 memahami interaksi antara syarat perlu dan syarat cukup dan memiliki peluang untuk membuktikan suatu teorema lebih dari satu cara (Crowley, 1987:3).

Van Hiele menyatakan bahwa hasil pemikiran mahasiswa pada tingkat 4 adalah perbandingan dan perbedaan yang terdapat pada sistem aksioma dalam geometri (Van de Wall, 2001:310). Pada tingkat ini mahasiswa tidak hanya melakukan pengambilan 
kesimpulan berdasarkan suatu sistem tapi sistem itulah yang menjadi kajiannya. Mahasiswa dapat bekerja pada sistem aksioma yang bermacam-macam, geometri nonEuclid dapat dipelajari, serta perbedaan sistem dapat dibandingkan. Geometri dipandang secara abstrak (Crowley, 1987:3).

Van Hiele menjelaskan bahwa tingkat berpikir dalam geometri itu berurutan yang berarti bahwa untuk mencapai tingkat yang lebih tinggi, mahasiswa perlu melalui tingkat berpikir sebelumnya secara urut. Kemajuan tingkat berpikir mahasiswa menuju tingkat berpikir yang lebih tinggi lebih dipengaruhi oleh strategi pembelajaran daripada umur. Masing-masing tingkat berpikir memiliki bahasa simbol (linguistic symbol) untuk dapat memahami sistem relasi yang terdapat pada materi geometri (Crowley, 1987).

Di bawah ini disajikan indikator tingkat berpikir berdasarkan teori van Hiele pada Tabel 1 berikut.

Tabel 1. Indikator Tingkat Berpikir Berdasarkan Teori van Hiele Pada Materi Segi Banyak

Tingkat berpikir Van

Hiele

Tingkat 0 Obyek pemikiran mahasiswa (visualisasi) masih didominasi bentuk dan seperti apa bentuk itu terlihat secara visual.

Tingkat 1 mahasiswa mulai mengenali (analisis) dan mengaplikasikan suatu ide geometri, mendeskripsikan dengan benar berbagai sifat serta dapat mengidentifikasi gambar sebagai bagian dari gambar yang lebih besar.
Indikator Tingkat Berpikir

- Mahasiswa dapat mengidentifikasi unsur-unsur segitiga

- Siswa dapat mengidentifikasi hubungan sebuah garis dan segitiga berdasarkan gambar

- mahasiswa dapat mengidentifikasi jenis-jenis segitiga berdasarkan gambar.

- mahasiswa dapat menyebutkan alasan mengenai bilangan triple pythagoras

- mahasiswa dapat menentukan jenis-jenis segiempat

Tingkat 2 mahasiswa dapat mengurutkan (deduksi dan mengaitkan beberapa ideinformal) ide geometri secara logis, memahami definisi, dan menarik kesimpulan dengan memberikan argumen secara informal.

- mahasiswa dapat membuat kesimpulan dengan memberikan penjelasan secara informal tentang materi yang disampaikan

- mahasiswa dapat membedakan jenis-jenis segi banyak

\begin{tabular}{cllll}
$\begin{array}{c}\text { Tingkat 3 } \\
\text { (deduksi) }\end{array}$ & $\begin{array}{l}\text { mahasiswa memahami arti } \\
\text { deduksi sehingga dapat } \\
\text { membuktikan dengan dengan } \\
\text { dasar aksioma maupun } \\
\text { teorema. }\end{array}$ & $\begin{array}{l}\text { mahasiswa dapat membuk- } \\
\text { tikan dengan memberikan } \\
\text { penjelasan secara formal } \\
\text { berdasarkan aksioma atau teorema. }\end{array}$ \\
& & & $\begin{array}{l}\text { Mahasiswa dapat membuk- } \\
\text { tikan teorema kongruensi dan } \\
\text { kese-bangunan }\end{array}$ \\
\hline $\begin{array}{c}\text { Tingkat 4 } \\
\text { (rigor) }\end{array}$ & $\begin{array}{l}\text { mahasiswa tidak hanya } \\
\text { melakukan pengambilan ke- }\end{array}$ & $\begin{array}{l}\text { - mahasiswa dapat membuk- } \\
\text { tikan kongruensi antar dua segitiga }\end{array}$ \\
\hline
\end{tabular}




\begin{tabular}{cll}
$\begin{array}{c}\text { Tingkat } \\
\text { berpikir Van } \\
\text { Hiele }\end{array}$ & \multicolumn{1}{c}{ Karakteristik } & \multicolumn{1}{c}{ Indikator Tingkat Berpikir } \\
\hline & $\begin{array}{l}\text { simpulan berdasarkan suatu } \\
\text { sistem tapi sistem itulah yang } \\
\text { menjadi kajiannya. }\end{array}$ & $\begin{array}{l}\text { berdasarkan teorema-teorema dan } \\
\text { postulat-postulat. }\end{array}$ \\
& $\begin{array}{l}\text { mahasiswa dapat membuk- } \\
\text { tikan kesebangunan antar dua } \\
\text { segitiga berdasarkan teorema- } \\
\text { teorema dan postulat-postulat }\end{array}$ \\
\hline
\end{tabular}

Hasil dari pemikiran mahasiswa pada tingkat ini adalah sistem deduktif aksiomatik dari geometri yang berarti bahwa mahasiswa sudah dapat membuktikan dengan dasar aksioma maupun teorema (van de Wall, 2001:310). Van Hiele menyatakan bahwa hasil pemikiran mahasiswa pada tingkat 4 adalah perbandingan dan perbedaan yang terdapat pada sistem aksioma dalam geometri (Van de Wall, 2001:310).

Mahasiswa hanya dapat mengerti tentang konsep Geometri yang sesuai dengan tingkat berpikirnya. Perbedaan kriteria pada setiap tingkat berpikir menyebabkan mahasiswa berbeda dalam memahami dan menyelesaikan soal. Sehingga masing-masing tingkat berpikir mahasiswa tersebut dapat dilihat dari jawaban mahasiswa ketika menyelesaikan soal.

Secara alamiah kemampuan mahasiswa dalam menyelesaikan soal Geometri berbeda-beda. Selain itu, mahasiswa juga dapat berbeda dalam cara pendekatan terhadap situasi belajar, dalam cara menerima, mengorganisasi dan menghubungkan pengalamanpengalaman mereka. Perbedaan-perbedaan individual yang menetap dalam cara menyusun dan mengelola informasi serta pengalaman-pengalaman tersebut dikenal dengan gaya kognitif. Witkin (1976) yang menyatakan bahwa, "gaya kognitif digunakan sebagai mediator kinerja siswa dalam mempelajari geometri...”(Perdikaris, 2011:40). Gaya kognitif akan mempengaruhi masing-masing mahasiswa dalam memahami materi dan permasalahan geometri karena mahasiswa memiliki cara yang khas dalam menyusun dan mengolah informasi selama mempelajari Geometri.

Winkel (1996: 147) mengemukakan pengertian gaya kognitif sebagai cara khas yang digunakan seseorang dalam mengamati dan beraktivitas mental di bidang kognitif, yang bersifat individual dan kerapkali tidak disadari dan cenderung bertahan terus. Desmita menyatakan bahwa "gaya kognitif adalah karakteristik individu dalam penggunaan fungsi kognitif (berpikir, mengingat, memecahkan masalah, membuat keputusan, mengorganisasi dan memproses informasi)" (2009:146). Hal ini berarti bahwa setiap individu memiliki gaya kognitif yang berbeda dalam memproses atau menghadapi suatu tugas dan masalah khususnya geometri. Hal ini didukung dengan pendapat Witkin (1976) yang menyatakan, "The cognitive styles are used as mediators of student 
geometric performance and as a tool to understand anomalies in the hierarchy of geometric development" (Perdikaris, 2011:40)

Gaya kognitif, dapat dibedakan berdasarkan perbedaan psikologis yaitu: gaya kognitif field independent (FI) dan field dependent (FD). Seorangyangmemilikigayakognitif field independent (FI) cenderungkurangbegitu tertarik denganfenomena sosial dan lebih suka dengan ide-ide dan prinsip-prinsip yang abstrak, kuranghangatdalamhubungan interpersonal,dalammengerjakan tugasnya merasa efisienbekerja sendiri. Orang yang memilikigaya kognitif field dependent (FD)dikategorikansebagaiseorang yang dapat berpikir secaraglobal, berperilaku sensitif secara sosial dan berorientasi interpersonal, lebih suka bekerja kelompok dalammengerjakan tugasnya.

Adanya perbedaan gaya kogntif mempengaruhi pola pikir dan perilaku mahasiswa. Mahasiswa dengan gaya kognitif FI akan mempunyai pola pikir yang berbeda dengan mahasiswa dengan gaya kognitif FD. Witkin dalam Elkind \& Weiner (1978:214) mengatakan bahwa: "Orang yang mempunyai gaya kognitif field independent merespon suatu tugas cenderung bersandar atau berpatokan pada syarat-syarat dari dalam diri sendiri, sedangkan orang yang memiliki gaya kognitif field dependent melihat syarat lingkungan sebagai petunjuk dalam merespon suatu stimulus.

Nurdin (2005) menjelaskan bahwa orang FD melihat syarat lingkungan sebagai petunjuk dalam merespon suatu stimulus dan memandang informasi secara umum. Sedangkan orang FI merespon suatu tugas cenderung bersandar atau berpatokan pada syarat-syarat dari dalam diri sendiri dan mampu menganalisanya kedalam bagian-bagian lebih rinci.

Field-independent individuals, who are characterized by confidence in internal references and in their own criteria, tend to assume an analytical approach towards information that allows them to break it down into its component parts and restructure it according to their needs(Tinajero, 2012). Lebih lanjut, Tinajero mengungkapkan bahwa, In contrast, individuals with a field-dependent style are more sensitive to external clues and thus tend to take information exactly as it is presented to them, and in what appears to be an effort to capture the structure of this information, they normally attend to its global aspects.

Dengan adanya identifikasi mengenai tingkat berpikir dan gaya kognitif mahasiswa akan memberikan pengetahuan baru bagi dosen. Dosen akan mendapat gambaran bahwa beberapa mahasiswa mungkin membutuhkan bantuan dalam memahami konsep penting dari materi sehingga mereka dapat mengerjakan soal dengan baik dan 
benar. Oleh karena itu, apabila dosen mengetahui tingkat berpikir mahasiswa dalam mempelajari geometri serta gaya kognitifnya, maka dosen dapat menentukan strategi dalam mengarahkan mahasiswa menuju tingkat berpikir yang lebih tinggi.

\section{METODE PENELITIAN}

Penelitian yang dilakukan merupakan metode penelitian deskriptif dengan pendekatan penelitian kualitatif dan teknik penelitian studi literatur tentang tingkat berpikir mahasiswa ditinjau dari gaya kognitif.

Data dalam penelitian ini adalah tingkat berpikir mahasiswa ditinjau dari gaya kognitif pada mata kuliah Geometri. Sumber data pada penelitian ini adalah berupa hasil observasi, hasil tes GEFT, tes diagnostik dan hasil wawancara terhadap mahasiswa pendidikan matematika semester 1 FKIP universitas Veteran Bangun Nusantara kabupaten Sukoharjo.

The Group Embedded Figure Test (GEFT) adalah instrumen yang sering digunakan untuk mengukur derajat wilayah ketergantungan seseorang (degree of fielddependency). Altun\& Cakan (2006:14) menjelaskan bahwa instrumen GEFTmerupakan tes yang non verbal dan sifat dari psikometrik tes telah diuji dalam lintas budaya. Witkin et al.(1971) dalam Bostic (1998:87) menyebutkan koefisien reliabilitas tes dari GEFT yaitu 0.82 yang diberikan pada siswa laki-laki dan perempuan.

GEFT terdiri dari 25 item berupa gambar kompleks yang dibagi menjadi tiga bagian pengerjaan selama 15 menit. Bagian pertama berisi tujuh item untuk latihan, bagian kedua dan bagian ketiga masing-masing berisi sembilan item untuk ujian dan penilaian. Skor total diperoleh dari sejumlah gambar yang berhasil atau benar dalam pencarian gambar kompleks pada bagian dua dan tiga pengerjaan tes. Skor totalnya adalah 18 dimana tiap jawaban benar dinilai 1 dan salah dinilai 0.Berikut skor GEFT menurut Bostic (1998:191) dilihat pada Tabel 2.

Tabel 2. Interpretasi Skor GEFT

\begin{tabular}{llcc}
\hline Kategori & Skor siswa laki-laki & $\begin{array}{c}\text { Skor } \\
\text { perempuan }\end{array}$ & siswa \\
\hline Strongly FD & $0-9$ & $0-8$ & \\
Slighty FD & $10-12$ & $9-11$ & \\
Slighty FI & $13-15$ & $12-14$ & \\
Strongly FI & $16-18$ & $15-18$ & \\
\hline
\end{tabular}

Teknik pengumpulan data menggunakan observasi, tes dignostik dan tes GEFT, wawancara. Observasi dalam pengumpulan data dilakukan dengan mengamati kegiatan belajar mengajar di kelas. Tes diagnostic dilakukan untuk melihat tingkat berpikir mahasiswa berdasarkan teori Van Hiele, sedangkan tes GEFT untuk mengetahui untuk 
melihat gaya kognitif lalu wawancara dilakukan untuk untuk mengetahui lebih jauh tentang tingkat berpikir.

Teknik analisis data dilakukan dengan reduksi data, penyajian data, simpulan dan verifikasi Reduksi data dilakukan saat pengambilan subjek sebagai data. Peneliti memberikan tes GEFT dan tes diasgnostik. Dari hasil kedua tes kemudian dianalisis. Selanjutnya data yang sama akan diambil salah satu yang selanjutnya dilakukan wawancara terhadap subjek yang telah direduksi. Jika terdapat data yang dapat memberikan informasi, maka data tersebut digunakan.

Penyajian data dilakukan dengan teks yang bersifat naratif. Data dari sampel dianalisis menggunakan kata-kata yang mendeskripsikan tingkat tingkat berpikir mahasiswa ditinjau dari gaya kognitif. Penarikan kesimpulan dilakukan setalah peneliti melakukan triangulasi metode antara tes diagnostik dan wawancara. Dari hasil kesimpulan akan didapatkan tingkat berpikir mahasiswa pada mata kuliah Geometri yang memiliki gaya kognitif Field Independent (FI) dan tingkat berpikir mahasiswa pada mata kuliah Geometri yang memiliki gaya kognitif Field Dependent (FD).

\section{HASIL DAN PEMBAHASAN}

Mahasiswa pada mulanya diberikan tes GEFT dimana peneliti memberikan instrumen tes GEFT kepada 35 mahasiswa dengan waktu pengerjaan 30 menit. Mahasiswa mengerjakan dengan sungguh-sungguh tanpa ada yang bertanya atau mengalami kesulitan saat menjawab pertanyaan. Dalam penelitian ini, tes GEFT digunakan untuk mendapatkan data mengenai gaya kognitif yang dimiliki mahasiswa yaitu gaya kognitif Field Dependent (FD) dan gaya kognitif Field Independent (FI).

Instrumen tes GEFT yang digunakan untuk tes merupakan instrumen baku, akan tetapi peneliti melakukan proses validasi terkait dengan penggunaan bahasa yang terdapat pada instrumen tersebut. Peneliti melakukan perubahan maupun penambahan pertanyaan pada tes GEFT dengan mengacu pada instrument baku tes GEFT. Validasi dilakukan kepada dosen pendidikan bimbingan konseling yang menjadi konselor. Dari hasil validasi didapatkan bahwa terdapat beberapa revisi berupa bahasa yang harus sedikit diubah agar tidak menimbulkan persepsi ganda.

Instrumen GEFT memiliki skor baku dalam mengelompokkan siswa dengan gaya kognitif FD dan FI. Sehingga peneliti memberikan tes GEFT kepada mahasiswa yang berjumlah 35 mahasiswa terdiri atas 19 siswa untuk kelas A dan 16 siswa untuk kelas B. Hasil pengelompokan gaya kognitif mahasiswa disajikan dalam Tabel 3 berikut. 
Tabel 3. Hasil Pengelompokan Gaya Kognitif Mahasiswa

\begin{tabular}{ccc}
\hline Kelas & \multicolumn{3}{c}{ Gaya Kognitif } \\
\cline { 2 - 3 } & FD & FI \\
\hline A & 14 & 5 \\
\hline B & 11 & 5 \\
\hline Jumlah & 25 mahasiswa & 10 mahasiswa \\
\hline
\end{tabular}

Berdasarkan tes GEFT yang dilakukan terhadap mahasiswa kelas A dan B diperoleh gambaran bahwa kedua kelas tersebut didominasi oleh mahasiswa-mahasiswa dengan gaya kognitif FD. Dimana ada kelas A terdapat 14 mahasiswa dan 11 mahasiswa pada kelas B. Sedangkan pada gaya kognitif FI baik kelas A maupun kelas B sama-sama terdapat 5 orang mahasiswa. Sehingga dapat dikatakan bahwa lebih dari 50\% mahasiswa pada semester 1 FKIP universitas Veteran Bangun Nusantara kabupaten Sukoharjo.memiliki gaya kognitif FD.

Setelah diketahui gaya kognitif mahasiswa pada kedua kelas dengan memberikan tes GEFT, selanjutnya diberikan tes diagnostik untuk mengetahui tingkat berpikir mahasiswa dan pada tahap ini akan didapatkan subjek penelitian. Tes diberikan kepada seluruh mahasiswa dengan waktu pengerjaan 40 menit. Soal yang diberikan berjumlah 4 butir dengan sub materi titik, garis dan bidang. Soal pada tes diagnostic ini berupa tes uraian. Soal sebelum diujikan melalui proses validasi terlebih dahulu. Validasi dilakukan kepada salah satu dosen pendidikan matematika Universitas Veteran Bangun Nusantara kabupaten Sukoharjo.

Setelah mendapatkan jawaban dari mahasiswa, peneliti lalu menganalisis untuk melihat tingkat berpikir mahasiswa. Dari hasil analisis didapatkan 5 mahasiswa yang selanjutnya menjadi subjek penelitian yang akan diteliti lebih lanjut. Berikut adalah tingkat berpikir masing-masing subyek seperti pada Tabel 4 .

Tabel 4. Tingkat Berpikir Masing-Masing Subyek

\begin{tabular}{ccc}
\hline Gaya Kognitif & Subyek & Tingkat Berpikir Van Hiele \\
\cline { 2 - 3 } & FD & Visualisasi (tingkat 0) \\
& AB & Pra Analisis \\
& & (Tingkat 1 yang belum sempurna) \\
\hline FI & BA & Visualisasi (tingkat 0) \\
& BB & Analisis (tingkat 1) \\
\cline { 2 - 3 } & BC & Pra Deduksi Informal \\
& & (Tingkat 2 yang belum sempurna) \\
\hline
\end{tabular}

Berdasarkan hasil analisis yang telah dipaparkan sebelumnya maka terdapat luaran berupa temuan bahwa terdapat 2 tingkat berpikir yang berbeda dengan tingkat berpikir Van Hiele, yaitu pada tingkat 1 dan tingkat 2. Pada tingkat 1 terdapat subjek 
yang tidak memenuhi indicator pada tingkat berpikir 1, sehingga dikatakan bahwa subjek tersebut berada pada tingkat 1 yang belum sempurna (Pra Analisis). Begitu pula pada tingkat 2 terdapat subjek yang tidak memenuhi indicator pada tingkat berpikir 2, sehingga dikatakan bahwa subjek tersebut berada pada tingkat 2 yang belum sempurna (Pra Deduksi Informal). Setelah didapat data tersebut, masing-masing subjek diwawancarai dimana selanjutntya hasil dari wawancara ditriangulasikan dengan data hasil tes guna mendapatkan tingkat berpikir mahasiswa. Teknik wawancara yang digunakan adalah wawancara terstruktur, dimana peneliti mempunyai pedoman wawancara yang berisi tentang pertanyaan-pertanyaan secara runtut dan detail agar mendapatkan informasi yang akurat.

Berdasarkan hasil triangulasi, didapatkan bahwa pada subjek yang mempunyai gaya kognitif FD memiliki tingkat berpikir Visualisasi (tingkat 0) dan Pra Analisis (Tingkat 1 yang belum sempurna). Sedangkan pada subjek yang mempunyai gaya kognitif FI memiliki tingkat berpikir Visualisasi (tingkat 0), Analisis (Tingkat 1), dan Pra Deduksi Informal (Tingkat 2 yang belum sempurna).

\section{SIMPULAN DAN SARAN}

Simpulan pada penelitian ini ialah.(1) tingkat berpikir mahasiswa pada mata kuliah Geometri yang memiliki gaya kognitif Field Dependent (FD) adalah visualisasi dan pra analisis, (2) tingkat berpikir mahasiswa pada mata kuliah Geometri yang memiliki gaya kognitif Field Dependent (FD) adalah visualisasi, analisis, dan pra deduksi informal.

Saran yang dapat diberikan oleh peneliti ialah penelitian ini dapat digunakan pada mata kuliah yang lain serta dapat digunakan sebagai rujukan penelitian pada bidang lain. Sedangkan saran kepada dosen, bahwa dosen harus lebih memperhatikan tentang tingkat berpikir dan gaya kognitif mahasiswa agar dosen dapat mengetahui metode apa yang digunakan saat mengajar ataupun gaya mengajar yang dilakukan saat menyampaikan materi agar materi dapat tersampaikan dengan baik dan tepat.

\section{DAFTAR PUSTAKA}

Abdi, A. (2012). A study on the relationship of thinking styles of students and their critical thinking skills. Procedia - Social and Behavioral Sciences. 47,719-1723

Altun, A., \& Cakan, M. (2006). Undergraduate Students' Academic Achievement, Field Dependent/Independent Cognitive Styles and Attitude toward Computers. Educational Technology \& Society, 9 (1), 289-297. 
Altun, M. (2008). ilkögretim ikinci Kademe (6, 7 ve 8. Sinıflarda) Matematik Ögretimi, 5. Baskı, Bursa: Aktüel Yayınları.

Bostic, J.F. (1988). Dissertation: "Cognitive Styles: Their Consolidation and Relationship, Beyond Cognitive Developmental Level and Critical Thinking Ability to Understanding Science”. Texas: Texas Tech University.

Carnine, M. (1997). Instructional design in Mathematics for student with learning disabilities Journal of Learning Disabilities 30:130-141

Chazan, D. (1993). High school geometry students' justification for their views of empirical evidence and mathematical proof. Educational Studies in Mathematics, 24(4), 359-387.

Crowley, Mary L. (1987). The van Hiele Model of the Development of Geometric Thought.Learning and TeachingGeometry, K-12,Yearbook of the National Council of Teachers of Mathematics, pp.1-16.

Desmita. (2009). Psikologi Perkembangan Peserta Didik. Bandung: PT Remaja Rosdakarya.

Elkind, D \& Weiner, I. B. (1978). Development of The Child. New York : John Willey and Sons.

Healy, L. \& Hoyles, C. (2000). A study of proof conceptions in algebra. Journal for Research in Mathematics Education, 31(4), 396-428.

Hoffer, Allan. (1981). Geometry is More Than Proof.NCTM. 74(1)

Karimah, R.K.N., Kusmayadi, T.A., \& Pramudya, I.(2018). Analysis of difficulties in mathematics learning on students with guardian personality type in problemsolving HOTS geometry test. Journal of Physics: Conference Series.

Kuzle, A. (2013). Patterns of metacognitive behavior during mathematics problemsolving in a dynamic geometry environmentInt. Electronic J. Math.Edu.8, 20-40.

Miles, Mattew B. \& A. Michael Huberman. (1992). Analisis Data Kualitatif: Buku Sumber Tentang Metode-Metode Baru. Terjemahan Tjetjep Rohendi Rohidi. Jakarta: Universitas Indonesia (UI-Press).

Mohd, N \& Mahmood, T.F.P. (2011). The Effects of Attitude towards Problem Solving in Mathematics Achievements. Australian Journal of Basic and Applied Sciences. 5(12): 1857-1862.

Moleong, L.J. (2008). Metodologi Penelitian Kualitatif. Bandung: Rosdakarya.

Nurdin. (2005). Analisis Hasil Belajar Matematika Berdasarkan Gaya Kognitif Guru dan Gaya Kognitif Siswa pada Kelas II SMU Negeri 3 Makassar. Jurnal Pendidikan dan Kebudayaan, 63(2).

Perdikaris, S.C. (2011). Using the Cognitive Style to Explain an Anomaly in the Hierarchy of the van Hiele Levels. Journal of Mathematical Sciences \& Mathematics Education, 6(2). 
Purwanto, N. (2010). Psikologi Pendidikan.Bandung: PT.Remaja Rosdakarya.

Santrock, J.W. (2007). Perkembangan Anak. Terj. Mila Rahmawati. Jakarta : Erlangga

Sutopo, H.B. (2002). Metodologi Penelitian Kualitatif. Surakarta: UNS Press

Tinajero, C., Lemos, S.M., Araújo, M., Ferraces, M.J., Páramo, M.F. (2012). Cognitive style and learning strategies as factors which affect academic achievement of brazilian university students. sicol. Reflex. Crit. 25 (1).

Van de Walle, John A. (2001). GeometricThinking and Geometric Concepts. In Elementary and Middle School Mathematics: Teaching Developmentally, 4th ed. Boston: Allyn and Bacon

Van Hiele, P. M. (1959/1986). The child's thought and geometry. In D. Fuys, D. Geddes, \& R. Tishchler (Eds.), English translation of selected writings of Dina van HieleGeldof and Pierre M. van Hiele (pp. 243-252).

Winkel, W. S. (1996). Psikologi Pengajaran. Edisi Revisi. Jakarta: Grasindo.

Witkin, H.A., Moore, C.A., Goodenough, D.R \& Cox, P.W. (1977). Field-dependent and Field-independent Cognitive style and Educational Implications. Review of Educational Research 47. 1-64.

Zhang, L.F. (2003). Contributions of Thinking Styles to Critical Thinking. Journal of Psychology, 137 (6). 